\title{
Maternal history and second trimester uterine artery Doppler in the assessment of risk for development of early and late onset pre-eclampsia and intra uterine growth restriction
}

\author{
Humera Noor $^{1 *}$, Mahapara Manzoor ${ }^{1}$, Saima Sadiq $^{1}$, Naveed Shahzad ${ }^{2}$
}

\author{
${ }^{1}$ Department of Obstetrics and Gynaecology, Government Medical College, Srinagar, India \\ ${ }^{2}$ Department of Health and Medical Education, Kashmir, India
}

Received: 11 March 2016

Accepted: 07 April 2016

\author{
*Correspondence: \\ Dr. Humera Noor, \\ E-mail: drhumeranoor@gmail.com
}

Copyright: () the author(s), publisher and licensee Medip Academy. This is an open-access article distributed under the terms of the Creative Commons Attribution Non-Commercial License, which permits unrestricted non-commercial use, distribution, and reproduction in any medium, provided the original work is properly cited.

\begin{abstract}
Background: To evaluate the value of one step uterine artery Doppler and maternal history in the prediction of early onset pre-eclampsia and intra uterine growth restriction in a random population

Methods: This study was conducted from 2012 to 2014 Lalla Ded hospital which is a tertiary care hospital associated with GMC Srinagar. This was a prospective study conducted on 200 pregnant women in the second trimester between 19-22 weeks of gestation. Singleton pregnant women were recruited from those attending antenatal care clinics at this hospital over a period of two years. Obstetric and medical history was taken. Transabdominal ultrasound was done and then patients were subjected to Doppler examination of uterine arteries.

Results: Mean age of study population was 26.3 years with maximum number of patients in 25-29 year age group. Total numbers of primigravida were $59.5 \%$. Maternal history revealed that $9.5 \%$ had previous history of hypertensive pregnancy, 3.5\% had history of IUGR. Early onset pre-eclampsia ( $<32$ weeks) was present in $42.9 \%$ and late onset pre-eclampsia (>32 weeks) was present in $57.1 \%$ cases. Doppler abnormalities were present in $7.5 \%$. In the patients who developed pre-eclampsia $57.1 \%$ had uterine artery Doppler abnormalities.

Conclusions: Maternal history and uterine artery Doppler at 19-22 weeks gestation is a single step test for the prediction of early onset $(<32$ weeks) and late onset pre-eclampsia and intra uterine growth restriction.
\end{abstract}

Keywords: Pregnancy, Primigravida, Pre-eclampsia, Doppler, IUGR

\section{INTRODUCTION}

Pre-eclampsia is a multi-factorial, multi-system disorder of human pregnancy defined by hypertension (BP $>140 / 90 \mathrm{~mm} \mathrm{Hg}$ ) and proteinuria after 20 weeks of gestation in a previously normotensive women. ${ }^{1}$ It is more common in women who are pregnant for the first time, who have a family or past history of hypertensive pregnancy. ${ }^{2}$ It is thought to be consequence of impaired trophoblastic invasion of the maternal spiral arteries and their conversion from narrow to wide non-muscular channels. ${ }^{3,4}$ The classic concept that pregnancy induced hypertension primarily originates from defective placentation has recently been challenged. The concept of early and late onset pre-eclampsia is more modern and widely accepted that two entities have different etiologies and should be regarded as different from the disease. ${ }^{5,6}$ Ness and Roberts suggested that it may be the common clinical end result of abnormal placentation as well as maternal factors. ${ }^{7}$

\section{Early onset pre-eclampsia $(<32 \text { weeks }>)^{8,9}$}

- Comprises small subgroup 5-20\%

- Impaired trophoblastic invasion of the spinal arteries.

- Uterine artery Doppler waveform abnormalities

- Signs of intra-uterine growth restriction 


\section{Late onset pre-eclampsia (>32 weeks) $)^{9}$}

- $>80 \%$ cases worldwide.

- Normal or slightly altered behaviour of the uterine arteries.

- Normally growing baby with or without signs of IUGR.

With the use of Doppler technology it has been possible to show a strong positive correlation between uterine artery vascular resistance expressed by an increased pulsatility index or a diastolic notch in pregnancy having pre-eclampsia or fetal growth restriction. ${ }^{10}$

The addition of maternal history to the uterine artery Doppler velocimetric studies in second trimester of pregnancy should be a single step for accurate prediction of pre-eclampsia and fetal growth restriction so as to allow judicious allocation of resources for monitoring and preventive measures to improve maternal and perinatal outcome.

\section{Aims and objectives}

1. To evaluate the value of one step uterine artery Doppler in the prediction of early onset preeclampsia and intrauterine growth restriction in a random population

2. To ascertain whether uterine artery Doppler and maternal history is effective in high risk pregnancies

3. To develop a predictive model for pre-eclampsia using maternal history and uterine artery Doppler.

\section{METHODS}

This study was conducted in Lalla Ded Hospital which is a referral/tertiary care Obstetric and Gynaecology Hospital in Srinagar city catering to whole Kashmir province. This was a prospective study conducted on 200 pregnant women in the second trimester between 19-22 weeks of gestation. Singleton pregnant women were recruited from those attending antenatal care clinics at this hospital over a period of two years. Both primigravida and multigravida were included. The examination was performed after explaining the procedure and an informed consent was taken from all the women. Women who agreed to participate in the study, a detailed Obstetrics and medical history was taken with reference to the history of PIH in the previous pregnancy, history of fetal size and weight in context of fetal growth restriction in the previous pregnancy was recorded. Transabdominal ultrasound was done for measurement of fetal growth and examination of fetal anomalies.

This study was conducted in Lalla Ded Hospital which is a referral/tertiary care Obstetrics and Gynaecology Hospital in Srinagar city catering to whole Kashmir province. This was a prospective study conducted on 200 pregnant women in the second trimester between 19-22 weeks of gestation. Singleton pregnant women were recruited from those attending antenatal care clinic at this hospital over a period of two years. Both primigravida and multigravida were included. The examination was performed after explaining the procedure and an informed consent was taken from all the women. Women who agreed to participate in the study, a detailed Obstetrics and medical history was taken with reference to the history of PIH in the previous pregnancy, history of fetal size and weight in context of fetal growth restriction in the previous pregnancy was recorded. Transabdominal ultrasound was done for measurement of fetal growth and examination of fetal anomalies.

\section{Inclusion criteria}

- All singleton pregnancies (primigravida and multigravida)

- Gestational age of 19-22 weeks

\section{Exclusion criteria}

- Twin pregnancy

- Fetal congenital or structural abnormalities

- Chronic hypertension (pre-gravid BP>140/90 $\mathrm{mmHg}$ )

- Renal disease

- Diabetes

Gestational age was calculated according to the date of last menstrual period and confirmed by a second trimester USG performed between 16 and 18 weeks of pregnancy, if there was a discrepancy (>10), USG was used to determine gestational age. In all cases baseline investigations like haemogram, blood group, blood group screening, LFT, KFT were evaluated. Ultrasound examination: for the USG examination the women were placed in supine position with $30^{\circ}$ left lateral tilt and real time sonography was done to determine the gestational age, presentation, placental localization, baby weight and amount of liquor.

\section{Doppler examination}

All the women were examined by the same observer, in dorsal decubitus position, table tilted at $45^{\circ}$. Equipment used to conduct the Doppler velocimetric study was GE, LOGIC $500 \mathrm{MD}$, MR3 Doppler machine, with the frequency of 3.5-5 MHz the wall filter was kept at a minimum and the images were recorded on an online computer. The Doppler study was performed simultaneously; vessels evaluated were the ascending branches of right and left uterine arteries. For the purpose of examination transducer was placed $2-3 \mathrm{~cm}$ towards the lateral wall of the uterus and downward medial to the anterior superior iliac spine directed toward the pelvis on each side, in a medially angulated position. The Doppler ultrasound was used to identify uterine artery homolateral to the transducer, on the intersection with the external iliac artery and the volume sample was placed approximately at $1 \mathrm{~cm}$ of the crossing point. The angle of 
insonation was maintained as low as possible and always less than $50^{\circ}$. The pulsatility index was measured and the presence or absence of early diastolic notch, either unilateral or bilateral was noted. The same was then repeated on the contralateral uterine artery and the mean pulsality index (mPI) was calculated.

Uterine artery Doppler results were considered to be abnormal if any of the subjects had:

1. Mean pulsatility index $(\mathrm{mPI})>95^{\text {th }}$ percentile.

2. Presence of diastolic notch.

An early diastolic notch was defined as V-shaped deflection towards the baseline in early diastole, just after systolic flow but prior to maximum diastolic flow. The criteria used to determine presence of a notch were those described by Bower et al: a notch was considered to be present 'no matter how small the notch was seen to be, from either uterine artery. ${ }^{11}$

\section{Mean Pulsatility Index (mPI)}

Pulsatility index of right uterine artery + Pulsatility index of left uterine artery/2.

Pre-eclampsia was defined according to the guidelines of the International Society for the study of hypertension in pregnancy. This required two recordings of diastolic blood pressure of $>90 \mathrm{mmHg}$ at least 4 hours apart in previously normotensive women, and proteinuria of 300 mg or more in 24 hours, or two recordings of at least ++ on dipstick analysis of midstream or catheter urine specimens, if no 24-hour collection was available. Fetal growth restriction was defined as a birth weight $<10^{\text {th }}$ percentile for gestation $^{17}$.

Every subject was followed up at 24, 28, 32 and 36 weeks with ultrasound scans, blood pressure measurements and urinalysis (24-hour) for proteins. Blood pressure was recorded at each antenatal visit in sitting position from the right arm using a mercury sphygmomanometer and was repeated after 4 hours at each antenatal visit. Fetal growth was assessed by USG. Women with normal as well as abnormal uterine artery Doppler were advised to come to the hospital immediately if abnormal symptoms, such as generalized edema, headache, blurred vision or epigastric pain existed. All subjects were then followed through the whole pregnancy period to see whether pre-eclampsia and fetal growth restriction developed or not. If preeclampsia developed, gestational age (in weeks) was noted and birth weight of the neonates was recorded and was correlated with the data pertaining to the maternal history and uterine artery Doppler findings.

For the purpose of analysis the study population was divided into:
Uncomplicated pregnancies (without pre-eclampsia, fetal growth restriction)

- $\quad$ Pre-eclampsia before 32 weeks (early onset).

- Pre-eclampsia after 32 weeks (late onset).

- Fetal growth restriction (birth weight less than $10^{\text {th }}$ percentile for gestation).

The statistical analysis was done by using Mann-Whitney $\mathrm{U}$ test. The data was expressed as mean +_ standard deviation (SD) and percentages. Any p-valueless than 0.05 i.e. $(\mathrm{p}<0.05)$ was considered to be significant. All data was managed and analyzed using the statistical package for

Social sciences (SPSS version 11.5) and MS excel software for data interpretation.

\section{RESULTS}

Table 1: Age distribution of subjects.

\begin{tabular}{|lll|}
\hline Age (year) & n & $\%$ \\
\hline $19-24$ & 64 & 32 \\
\hline $25-29$ & 96 & 48 \\
\hline $30-34$ & 40 & 20 \\
\hline mean \pm sd & $26.3 \pm 3.5(20,34)$ & \\
\hline Total & 200 & 100 \\
\hline
\end{tabular}

Table 2: Pre-eclampsia across the age (years) of studied subjects.

\begin{tabular}{|llll|r|}
\hline & & \multicolumn{2}{c|}{ Pre-eclampsia } & \\
& & Present & Absent & \\
\cline { 1 - 4 } $\begin{array}{l}\text { Age } \\
(y r s)\end{array}$ & $19-24$ & $5(35.7 \%)$ & $59(31.7 \%)$ & \\
\cline { 2 - 4 } & $25-29$ & $3(21.4 \%)$ & $93(50 \%)$ & Total \\
\cline { 2 - 4 } Total & & $6(42.9)$ & $34(18.3 \%)$ & \\
\hline
\end{tabular}

Table 3: IUGR across the age (years) of studied subjects.

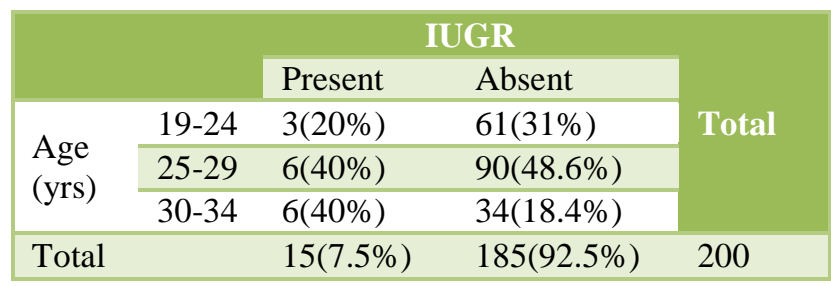

The present study was conducted in Lalla Ded hospital for a period of 2 years. A total of 200 singleton pregnancies were included in the study. After all baseline investigations, maternal history was recorded in all pregnant women and they were subjected to the Doppler velocimetric study. Doppler study of uterine artery was done. 
Table 4: Distribution of cases with respect to onset of pre-eclampsia.

\begin{tabular}{|c|c|c|c|c|}
\hline & & $\begin{array}{l}\text { Early } \\
\text { onset } \\
<32 \text { weeks }\end{array}$ & $\begin{array}{l}\text { Late } \\
\text { onset } \\
\geq 32 \text { weeks }\end{array}$ & \multirow{5}{*}{ Total } \\
\hline & & $\mathrm{n} \quad \%$ & $\%$ & \\
\hline \multirow{3}{*}{$\begin{array}{l}\text { Age } \\
\text { (yrs) }\end{array}$} & $19-24$ & 240 & 60 & \\
\hline & $25-29$ & 133.3 & 66.7 & \\
\hline & $30-34$ & 350 & 50 & \\
\hline Total & & $6(42.9 \%)$ & $8(57.1 \%)$ & 14 \\
\hline
\end{tabular}

Table 5: Parity wise PE and IUGR distribution of the studied population.

\begin{tabular}{|lllll|}
\multirow{2}{*}{ Parity } & \multicolumn{2}{l}{ Pre-eclampsia } & IUGR & \\
& Present & Absent & Present & Absent \\
\hline Primi & $9(64.3 \%)$ & $110(59.6)$ & $7(46.7 \%)$ & $112(60.5 \%)$ \\
\hline Multi & $5(35.75 \%)$ & $76(40.9 \%)$ & $8(53.3 \%)$ & $73(39.5 \%)$ \\
\hline
\end{tabular}

Table 6: Parity wise distribution of cases in relation to gestation age (weeks) of onset of PE.

\begin{tabular}{|c|c|c|c|c|c|c|}
\hline \multicolumn{6}{|c|}{ Pre-eclampsia } & \multirow{3}{*}{ Total } \\
\hline & & \multicolumn{2}{|c|}{$\begin{array}{l}\text { Early onset } \\
<32 \text { weeks }\end{array}$} & \multicolumn{2}{|c|}{$\begin{array}{l}\text { Late onset } \\
>32 \text { weeks }\end{array}$} & \\
\hline & & $\mathrm{n}$ & $\%$ & $\mathrm{~N}$ & $\%$ & \\
\hline \multirow{2}{*}{ Parity } & Primi & 4 & 66.7 & 5 & 62.5 & \\
\hline & Multi & 2 & 33.3 & 3 & 37.5 & \\
\hline Total & & 6 & & 8 & & 14 \\
\hline
\end{tabular}

Table 7: Blood pressure of the studied population.

\begin{tabular}{|ll|}
\hline BP & mean \pm sd \\
\hline Systolic BP(mmHg) & $118.6 \pm 14.2(110,156)$ \\
\hline Diastolic BP(mmHg) & $76.4 \pm 10.3(70,106)$ \\
\hline
\end{tabular}

Table 8: Maternal and family history in the studied subjects.

\begin{tabular}{|llll|}
\hline \multirow{4}{*}{$\begin{array}{l}\text { Maternal } \\
\text { history }\end{array}$} & IUGR & 7 & n \\
\cline { 2 - 4 } & PIH & 19 & 3.5 \\
\cline { 2 - 4 } & Still birth & 3 & 9.5 \\
\cline { 2 - 4 } $\begin{array}{l}\text { Family } \\
\text { history }\end{array}$ & IUD & 1 & 1.5 \\
\cline { 2 - 4 } & PIH & 8 & 0.5 \\
\hline
\end{tabular}

Table 9: Maternal history and family history wise distribution of PE.

\begin{tabular}{|llll|}
\hline & & \multicolumn{3}{c}{ Pre-eclampsia } \\
\hline Maternal & & Present & Absent \\
history & Absent & $8(57.1 \%)$ & $19(10.2 \%)$ \\
\hline $\begin{array}{l}\text { Family } \\
\text { history }\end{array}$ & Present & $6(42.9 \%)$ & $167(89.9 \%)$ \\
\cline { 2 - 4 } & Absent & $8(57.1 \%)$ & 165(88.7\%) \\
\hline
\end{tabular}

For the purpose of analysis study population was divided into those who had a normal course of the pregnancy, those who developed pre-eclampsia before 32 weeks, those who developed pre-eclampsia after 32 weeks and those who had fetal growth restriction.

Table 10: Doppler examination of the studied population.

\begin{tabular}{|lll|}
\hline Doppler & n & $\%$ \\
\hline Normal & 185 & 92.5 \\
\hline Diastolic notch & 4 & 2 \\
\hline Pulsatility index & 11 & 5.5 \\
\hline
\end{tabular}

Table 11: Doppler abnormalities detected among the pre-eclampsia.

\begin{tabular}{|llllllll|}
\hline \multirow{2}{*}{ Doppler } & \multicolumn{9}{c}{$\begin{array}{l}\text { Pre-eclampsia } \\
\end{array}$} & $\mathrm{n}$ & $\%$ & $\mathrm{n}$ & $\%$ & $\mathrm{n}$ & $\%$ \\
\hline Normal & 1 & 16.7 & 5 & 62.5 & 9 & 60 \\
\hline $\begin{array}{l}\text { Diastolic } \\
\text { notch }\end{array}$ & 2 & 33.3 & 1 & 12.5 & 2 & 13.33 \\
\hline $\begin{array}{l}\text { Mean } \\
\text { pulsality } \\
\text { index }\end{array}$ & 3 & 50.0 & 2 & 25 & 4 & 26.66 \\
\hline Total & 6 & & 8 & & 15 & \\
\hline
\end{tabular}

\section{DISCUSSION}

The analysis of age distribution showed that the mean age was 26.3 years. It was observed that there was statistically significant increased risk of pre-eclampsia among women who were in age group of 30-34 years with OR(Odds Ratio) of 3.6, this was comparable with study of FANG et al. ${ }^{12}$ The parity distribution revealed that majority of the women who developed pre-eclampsia were primigravida and this was consistent with study done by Odegard et al. ${ }^{13}$ The distribution of cases according to BMI even though non-significant statistically revealed that small increase even within normal range, significantly and independently increases a women's risk for pre-eclampsia. Women with a prior history of pregnancy associated with hypertensive disorder had a 9.3 fold increase in risk of pre-eclampsia. The association was particular in late onset preeclampsia. A family history of hypertension was associated with increase pre-eclampsia risk particularly late onset pre-eclampsia. This was consistent with studies done by Fang et al. ${ }^{12}$ In the present study uterine artery Doppler was used to screen a random population at 19-22 weeks of gestation. The advantage of using uterine arteries instead of small arcuate or radial arteries is that the uterine arteries reflects the total resistance to blood flow in the distal uteroplacental vasculature, whereas these smaller arteries do not reflect this resistance (Oosterhof et al). ${ }^{14}$ Pre-eclampsia was present in $7 \%$ of the study population which was similar to that reported by walker et al. ${ }^{15}$ IUGR was present in $7.5 \%$. In the 
women who developed pre-eclampsia uterine artery Doppler abnormalities were present in $57.1 \%$ and in women who had IUGR uterine artery Doppler abnormalities were present in $40 \%$. Doppler study of the uterine arteries had a sensitivity of $57.1 \%$ and specificity of $96.2 \%$ for pre-eclampsia and for IUGR it was $40 \%$ and $95.1 \%$ respectively.

In the study subjects who had pre-eclampsia of early onset ( $<32$ weeks), mean pulsatility index (Mpi) $>95^{\text {th }}$ percentile was present in $50 \%$ cases whereas in late onset group (>32 weeks) $\mathrm{mPI}>95^{\text {th }}$ percentile was present in only $25 \%$ cases. In cases who had IUGR mean pulsatility index $>95^{\text {th }}$ percentile was present in $33.33 \%$ cases. This was comparable with studies done by $\mathrm{Yu}$ et al $(2008)^{16}$ where $\mathrm{mPI}>95$ percentile was present in $43.8 \%$ cases. In women who developed pre-eclampsia before 32 weeks diastolic notch was present in $33.33 \%$ cases compared to the women who developed pre-eclampsia after 32 weeks where notch was present in only $12.5 \%$ cases. In cases that had IUGR, notch was present in $11.1 \%$. The finding from the present study show that the uterine artery Doppler in the second trimester of pregnancy can identify $83.33 \%$ of pregnancies that will subsequently develop early onset pre-eclampsia ( $<32$ weeks) and $40 \%$ of pregnancies who will have IUGR.

In early onset (<32 weeks) pre-eclampsia, IUGR was present in $66.7 \%$ and in late onset ( $>32$ weeks) IUGR was present in $33.3 \%$ cases. In present study uterine artery Doppler had a positive predictive value (PPV) of $53.5 \%$ and negative predictive value (NPV) of $96.8 \%$. In the present study the test result had a low sensitivity $(57.1 \%)$ and positive predictive value of $53.3 \%$ for preeclampsia. This test has a high negative predictive value $96.8 \%$ which implies that only $3.2 \%$ of women with normal Doppler results will develop pre-eclampsia.

\section{CONCLUSION}

From present study, we concluded that,

1. Single step uterine artery Doppler at 19-22 weeks gestation is a feasible test for the prediction of early onset ( $<32$ weeks) pre-eclampsia associated with IUGR.

2. Early onset (<32 weeks) pre-eclampsia associated with IUGR, defective placentation might have a causative role to play.

3. The combined model of second trimester uterine artery Doppler and maternal history helps us to categorize pre-eclampsia cases into early onset and late onset.

4. The combined model of second trimester uterine artery Doppler and maternal history can be used as a screening test for assessing the development of pre- eclampsia and IUGR and initiating appropriate preventive modalities.

Funding: Not required

Conflict of interest: None declared

Ethical approval: The study was approved by the Institutional Ethics Committee

\section{REFERENCES}

1. Brown MA, Lindheimer MD, De Swiet M, Van Assche A, Moutquin JM. The classification and diagnosis of the hypertensive disorders of pregnancy: statement from the international Society for the study of hypertension in pregnancy (ISSHP). Hypertens Pregnancy. 2001;20:ix-xiv.

2. Hjartardoltir S, Leifsson BG, Geirsson RT, Steinthrosdottir V. Paternity change and the recurrence risk in familial hypertensive disorder in pregnancy. Hypertension in pregnancy. 2004;23(2):219-25.

3. Pijnenborg R, Bland JM, Robertson WB, Brosens I. Uteroplacental arterial changes related to interstitial trophoblast migration in early humans pregnancy placenta. 1983:4397-413.

4. Lyall F. Priming and remodeling of human placental bed spiral arteries during pregnancy- a review. Placenta. 2005:31-6.

5. Von Dadelszen P, Magee LA, Roberts JM. Sub classification of pre-eclampsia. Hypertens pregnancy. 2003;22:143-8.

6. Huppertz B. Placental origins of preeclampsia challenging the current hypothesis. Hypertension. 2008;51:970-5.

7. Ness RB, Roberts JM. Heterogenous causes constituting single syndrome of preeclampsia: a hypothesis and its implication. Am J Obstet Gynecol. 1998;179:1317-23.

8. Murphy DJ, Striate GM. Mortality and morbidity associated with early onset pre-eclampsia. Hypertns Pregnancy. 2009;9:221-31.

9. Ness RB, Sibai BM. Shared and disparate components of the pathophysiology of fetal growth restriction and preeclampsia. Am J Obstet Gynecol. 2008;201:121-6.

10. Irion O, Masse J, Forest JC. Prediction of preeclampsia, low birthweight for gestation and prematurity by uterine artery blood flow velocity waveforms analysis in low risk nulliparous women. Br J Obstet Gynaecol. 1998;105:422-9.

11. Bower $\mathrm{S}$, Bewley $\mathrm{S}$, Campbell $\mathrm{S}$. Improved prediction of pre-eclampsia by screening of uterine arteries using the early diastolic notch and color Doppler imaging. Obstet Gynecol. 1993;82:78-83.

12. Fang R, Dawson A, Vitool L. Williams asian biomedicine. 2009;5:477-86

13. Odegard RA, Vatten LJ, Nilsen ST. Risk factors and clinical manifestations of pre-eclampsia. BJOG. 2000;107:1410-6.

14. Oosterhof H, Aaanoudse JG. Ultrasound pulsed Doppler studies of the uteroplacental circulation. The 
influence of sampling site and placental implantation. Gyn Obstet Invest. 1992;33;75-79.

15. Walker JJ. Pre-eclampsia. Lancet 2000;356:1260-5.
16. Yu CK, Khouri O, Onwudine N. Prediction of preeclampsia by uterine artery Doppler imaging; relationship to gestational age at delivery. 2008;31:310-3.

Cite this article as: Noor $\mathrm{H}$, Manzoor M, Sadiq S, Shahzad N. Maternal history and second trimester uterine artery Doppler in the assessment of risk for development of early and late onset pre-eclampsia and intra uterine growth restriction. Int J Reprod Contracept Obstet Gynecol 2016;5:1571-6. 